\title{
KONSEP PEMROGRAMAN BERORIENTASI OBJECT (PBO) PADA DELPHI
}

EKA MEI RISTIANTI

165100091, 785567914

Fakultas Komputer

Ekameiristianti.student@umitra.ac.id

\begin{abstract}
Merupakan suatu bahasa pemrograman yang memberikan berbagai fasilitas pembuatan aplikasi untuk mengolah teks, grafik, angka, database dan aplikasi web. Program ini mempunyai kemampuan luas yang terletak pada produktifitas, kualitas, pengembangan perangkat lunak, kecepatan kompilasi, pola desain yang menarik serta bahasa pemrogramannya terstruktur dan lengkap. Fasilitas pemrograman dibagi dalam dua kelompok yaitu object dan bahasa pemrograman.
\end{abstract}

Object adalah suatu komponen yang mempunyai bentuk fisik dan biasanya dapat dilihat. Object biasanya dipakai untuk melakukan tugas tertentu dan mempunyai batasan-batasan tertentu. Sedangkan bahasa pemrograman dapat disebut sekumpulan teks yang mempunyai arti tertentu dan disusun dengan aturan tertentu untuk menjalankan tugas tertentu. Gabungan antara object dengan bahasa pemrograman sering disebut bahasa pemrograman berorientasi object.

OOP/PBO merupakan paradigma pemrograman yang popular saat ini yang telah menggantikan teknik pemrograman berbasis prosedur. Object Oriented Programing yang berarti pula Pemrograman Beorientasi Objek sudah ditemukan sekitar tahun 1960 dan dikembangkan pada permulaan tahun 1970.

Kata Kunci : Object Oriented Program (OOP) 


\section{A. INTRODUCTION}

\section{Borland Delphi}

Merupakan suatu bahasa pemrograman yang memberikan berbagai fasilitas pembuatan aplikasi untuk mengolah teks, grafik, angka, database dan aplikasi web. Program ini mempunyai kemampuan luas yang terletak pada produktifitas, kualitas, pengembangan perangkat lunak, kecepatan kompilasi, pola desain yang menarik serta bahasa pemrogramannya terstruktur dan lengkap. Fasilitas pemrograman dibagi dalam dua kelompok yaitu object dan bahasa pemrograman. Object adalah suatu komponen yang mempunyai bentuk fisik dan biasanya dapat dilihat. Object biasanya dipakai untuk melakukan tugas tertentu dan mempunyai batasanbatasan tertentu. Sedangkan bahasa pemrograman dapat disebut sekumpulan teks yang mempunyai arti tertentu dan disusun dengan aturan tertentu untuk menjalankan tugas tertentu. Gabungan antara object dengan bahasa pemrograman sering disebut bahasa pemrograman berorientasi object.

\section{Apa itu PBO?}

OOP/PBO merupakan paradigma pemrograman yang popular saat ini yang telah menggantikan teknik pemrograman berbasis prosedur. Object Oriented Programing yang berarti pula Pemrograman Beorientasi Objek sudah ditemukan sekitar tahun 1960 dan dikembangkan pada permulaan tahun 1970.

Pemrograman Berorientasi Objek (Object Oriented Programming/OOP) merupakan pemrograman yang berorientasikan kepada objek, dimana semua data dan fungsi dibungkus dalam class-class atau object-object. Setiap object dapat menerima pesan, memproses data, mengirim, menyimpan dan memanipulasi data. Beberapa object berinteraksi dengan saling memberikan informasi satu terhadap yang lainnya.

Masing-masing object harus berisikan informasi mengenai dirinya sendiri dan dapat dihubungkan dengan 
Object yang lain. Pemrograman berorientasi objek berbeda dengan pemrograman prosedural yang hanya menggunakan satu halaman kebawah untuk mengerjakan banyak perintah atau statement. Penggunaan pemrograman berorientasi objek sangat benyak sekali, contoh : java, php, perl, c\#, cobol, dan lainnya.

Dalam konsep Pemrograman Berorientasi Objek dikenal beberapa istilah umum, yaitu:

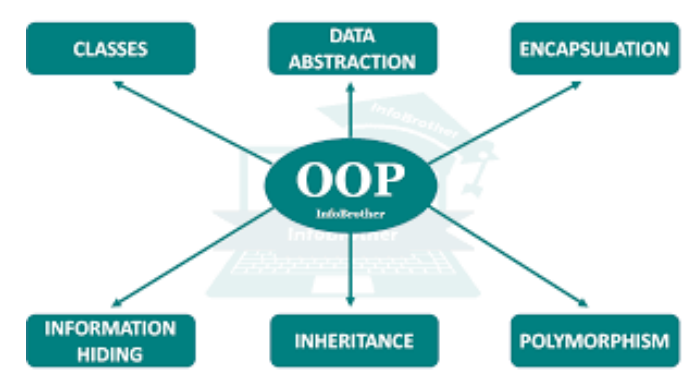

\section{Attribute}

Atribut dari sebuah kelas adalah variabel global yang dimiliki sebuah kelas, Atribut dapat memiliki hak akses private, public maupun protected.

Sebuah atribut yang dinyatakan sebagai private hanya dapat diakses secara langsung oleh kelas yang membungkusnya, sedangkan kelas lainnya tidak dapat mengakses atribut ini secara langsung

\section{Method}

Method adalah fungsi atau prosedur yang dibuat oleh seorang programmer didalam suatu Class. Dengan kata lain, method pada sebuah kelas hampir sama dengan fungsi atau prosedur pada pemrograman prosedural.

Pada sebuah method di dalam sebuah kelas juga memiliki izin akses seperti halnya atribut pada kelas, izin akses itu antara lain private, public dan protected yang memiliki arti sama pada izin akses atribut yang telah dibahas sebelumnya. Sebuah kelas boleh memiliki lebih dari satu method dengan nama yang sama asalkan memiliki parameter masukan yang berbeda sehingga kompiler atau interpreter dapat mengenali method mana yang dipanggil.

\section{Class}

Class didefinisikan sebagai sebuah blueprint(denah), atau prototipe, yang 
mendefiniskan variabel-variabel dan metode-metode yang umum untuk semua objek dari $n$ jenis tertentu (n maksudnya jumlah tertentu). Sebuah kelas menyerupai sebuah struktur yang merupakan tipe data sendiri, misalkan tipe data titik yang terdiri dari koordinat $\mathrm{x}$ dan $\mathrm{y}$. Bahasa Java telah menggunakan sebuah kelas untuk menyatakan tipe data titik karena bahasa pemrograman Java merupakan bahasa pemrograman berorientasi objek murni sehingga tidak mengenal struktur, melainkan mengenal apa yang disebut dengan kelas.

\section{Object}

Merupakan perwujudan dari class, setiap object akan mempunyai attribute dan method yang dimiliki oleh classnya, contohnya: amir, ahmad, yani merupakan object dari class manusia. Setiap object dapat berinteraksi dengan object lainnya meskipun berasal dari class yang berbeda.

Object merupakan sesuatu yang memiliki identitas (nama), pada umumnya juga memiliki data tentang dirinya maupun object lain dan mempunyai kemampuan untuk melakukan sesuatu dan bisa bekerja sama dengan objek lainnya. Pada dasarnya semua benda yang ada di dunia dapat dianggap sebagai sebuah object. Rumah, mobil, sepeda motor, meja, dan komputer merupakan contoh-contoh object yang ada di dunia nyata. Object adalah implementasi dari class. Secara sederhananya, dapat dikatakan terdiri dari properti (atribut) dan method.

Konsep-konsep dalam OOP/PBO :

\section{Abstraction}

Abstraksi merupakan kemampuan sebuah program untuk melewati aspek informasi yang diproses olehnya, yaitu kemampuan untuk memfokus pada inti. Setiap objek dalam sistem melayani sebagai model dari "pelaku" abstrak yang dapat melakukan kerja, laporan dan perubahan keadaannya, dan berkomunikasi dengan objek lainnya dalam sistem, tanpa mengungkapkan bagaimana kelebihan ini diterapkan. 
Proses, fungsi atau metode dapat juga dibuat abstrak, dan beberapa teknik digunakan untuk mengembangkan sebuah pengabstrakan.

\section{Encapsulation}

Merupakan suatu mekanisme untuk menyembunyikan atau memproteksi suatu proses dari kemungkinan interferensi atau penyalahgunaan dari luar sistem dan sekaligus menyederhanakan penggunaan sistem tersebut.

Memastikan pengguna sebuah objek tidak dapat mengganti keadaan dalam dari sebuah objek dengan cara yang tidak layak. Hanya metode dalam objek tersebut yang diberi ijin untuk mengakses keadaannya. Setiap objek mengakses interface yang menyebutkan bagaimana objek lainnya dapat berinteraksi dengannya. Objek lainnya tidak akan mengetahui dan tergantung kepada representasi dalam objek tersebut.

\section{Inheritance}

Merupakan konsep mewariskan attribute dan method yang dimiliki oleh sebuah class kepada class turunannya. Dengan konsep ini class yang dibuat cukup mendefinisikan attribute dan method yang spesifik didalamnya, sedangkan attribute dan method yang lebih umum akan didapatkan dari class yang menjadi induknya.

Mengatur polimorfisme dan enkapsulasi dengan mengijinkan objek didefinisikan dan diciptakan dengan jenis khusus dari objek yang sudah ada.Objek-objek ini dapat membagi (dan memperluas) perilaku mereka tanpa haru mengimplementasi ulang perilaku tersebut (bahasa berbasisobjek tidak selalu memiliki inheritas.

\section{Polymorphism}

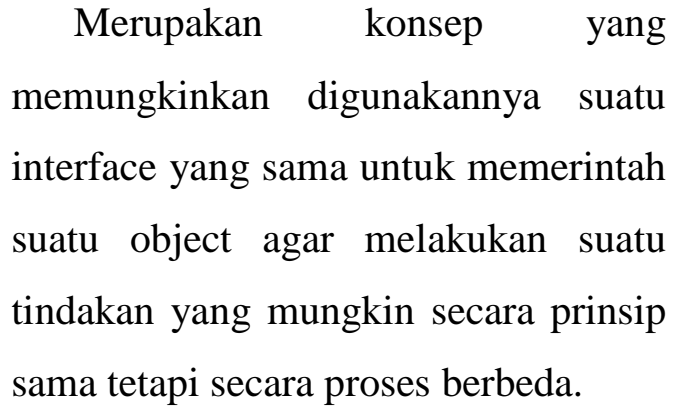


Model data berorientasi objek disebut dapat memberi fleksibilitas yang lebih, kemudahan mengubah program dan digunakan luas dalam teknik piranti lunak skala besar. Lebih jauh lagi, pendukung OOP mengklaim bahwa OOP lebih mudah dipelajari bagi pemula dibanding dengan pendekatan sebelumnya selain itu pendekatan OOP lebih mudah dikembangkan dan dirawat.

\section{B. CONTENT}

\section{Studi Kasus "Food Court 'Oishi $\mathrm{Ne}^{\prime \prime \prime}$}

Program OOP (Object Oriented Program) dengan Studi Kasus "Food Court 'Oishi $\quad \mathrm{Ne}^{\prime \prime \prime}$

Berikut analisa Kasusnya!

Food Court "Oishi Ne" merupakan rumah makan yang menyediakan makanan dimana masing-masing menu makanan disediakan dalam bentuk paket nama, menu paket dan harga.

Untuk menu minuman, Food Court 'Oishi Ne' menyediakan Air Mineral, berbagai macam Juice dengan harga yang sama dan Es Teh Manis

Agar lebih dekat dengan pelanggan dan meningkatkan pelayanan, Food Court 'Oishi $\mathrm{Ne}^{\prime}$ memberikan pelayanan tambahan yaitu delivery dan take away.

Proses Program:

1. Untuk memulai program, kasir harus menekan tombol bersih agar imputan transaksi seblumnya hilang dan semua objek dalam program siap digunakan.

2. Pelanggan memilih paket makanan yang akan dibeli. dengan memilih salah satu paket makan nama menu dan harga paket akan tampil di masing-masing textfield.

3. pelanggan menentukan jumla menu yang dibeli dengan tugas kasir adalah menginput jumlah beli sesuai dengan keinginan pelanggan. Dengan menekan tombol enter maka total harga yang harus dibayar oleh pelanggan akan tampil sesuai 
dengan kalkulasi harga paket dan jumlah yang dibeli.

4. Sebelum transaksi selesai, pelanggan diperbolehkan untuk memilih minuman.

5. Ketika diinput jumlah minumannya, maka total bayar akan bertambah sesuai dengan hasil kalkulasi pembelian minuman. Contoh: Jika total bayar 1000 dan pelanggan membeli air mineral 2 gelas dengan total harga 1000, maka total bayar menjadi 2000.

6. Begitu juga dengan jenis pelayanannya. Untuk pelayanan delivery, Food Court 'Oishi $\mathrm{Ne}^{\prime}$ memberikan tarif $10 \%$ dari total bayar. Sedangkan untuk take away tidak dikenakan tarif. Tarif pelayanan akan muncul otomatis disebuah TextField.

7. Sleanjutkan kasir akan menekan tombol 'Hitung' sehingga total bayar akan dijumlahkan dengan tarif pelayanannya.

8. Kasir akan menginput uang bayar yang diberikan pelanggan, Jika uangnya melebihi dari total yang harus dibayarkan, makan akan muncul otomatis uang kembaliannya.

9. Jika transaksi selesai maka kasir dapat menekan tombol keluar, dimana pada saat menekan tombol tersebut, program mengkonfirmasi kasir dengan memberikan pertanyaan "Apakah anda yakin ingin menutup aplikasi?". Jika kasir memilih Yes maka program ditutup dan sebaliknya.

Dari analisa tersebut diatas, maka designlah program tersebut dengan menggunakan Program PBO! Pertama, buatlah class java dengan Java Class yang diberi nama 'FormFood' (atau sesuaikan dengan keinginan anda)

Kemudian tulis coding dibawah ini pada Java Class yang anda buat tadi.

public class FormFood \{ 
public

String

paket,makan,minum,mnm,layan;

public int jml_mkn,jml_mnm;

public double hrg_mkn, hrg_mnm,biaya,ub,uk, ttl, total, ttlbyr;

public void setPaket ( String val)

\{ paket=val; \}

public String getPaket()

\{ return paket; \}

public void setPilihPaket ()

$\{$ if (paket.equalsIgnoreCase("PAKET

$\left.\left.1^{\prime \prime}\right)\right)$

I makan="Sayur Asem, Tempe

Goreng, Kerupuk";

hrg_mkn=7000; \}

else

(paket.equalsIgnoreCase("PAKET 2"))

$\{$ makan="Ayam Goreng, Sambel,

Balado Kentang";

hrg_mkn=10000; \}

else

if

(paket.equalsIgnoreCase("PAKET 3"))

$\{$ makan="Balado Telur, Sayur Lodeh,

Tahu";

hrg_mkn=8500; \}

else

$\{$ makan $="$ "; $\left.\left.h r g \_m k n=0 ;\right\}\right\}$

public void setMakan(String val)

$\{$ makan=val; $\}$

public String getMakan()

\{ return makan; \}

public void setHrgMkn(Double val)

$\left\{h r g \_m k n=v a l ;\right\}$

public double getHrgMkn()

\{ return hrg_mkn; \}

public void setJmlMkn(Integer val)

$\left\{j m l \_m k n=v a l ;\right\}$

public int getJmlMkn()

\{return jml_mkn; \}

public void setMinum (String val)

$\{$ minum $=$ val; $\}$

public String getMinum()

\{ return minum; \}

public void setPilihMinum()

$\{$ if ( minum.equalsIgnoreCase("ES

TEH MANIS"))

$\{$ hrg_mnm=2500; \}

else if

minum.equalsIgnoreCase("JUS"))

$\{$ hrg_mnm=5000; \} 


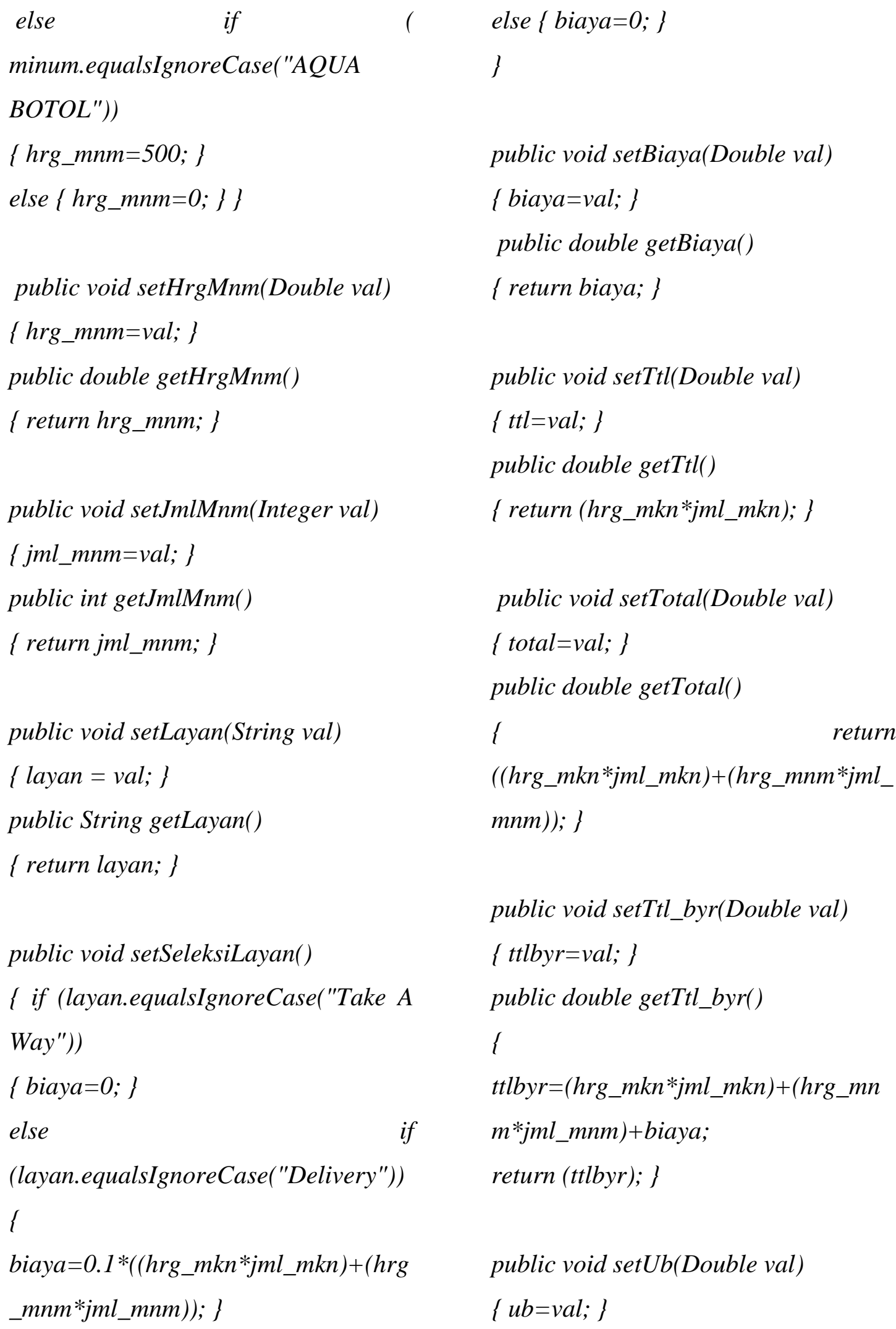


public double getUb()

\{ return $u b ;\}$

public double getUk()

$\{u k=u b-t t l b y r ;$

return $u k ;\}$

\}

Setelah membuat Class diatas, Buatlah program form dengan design sebagai berikut yang diberi nama 'FormFood1' :

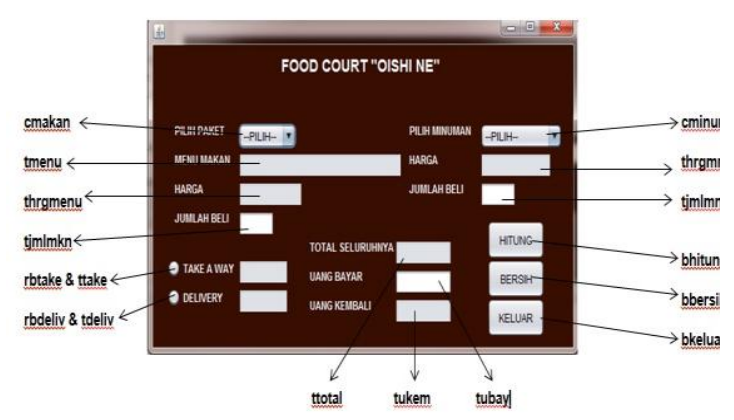

Berikut adalah listing coding yang di FormFood1:

import java.awt.event.KeyEvent;

import javax.swing.JOptionPane;

public class FormFoodl extends javax.swing.JFrame \{

FormFood food = new FormFood();

public FormFood1() \{ initComponents();
setLocationRelativeTo(this);

$\operatorname{bersih}()$;

nonaktif();

bhitung.setEnabled(false);

\}

private void

bbersihActionPerformed(java.awt.even t.ActionEvent evt) \{

// TODO add your handling code here:

$\operatorname{bersih}()$;

$\operatorname{aktif();}$

bhitung.setEnabled(true);

cmakan.requestFocus();

\}

private void

bkeluarActionPerformed(java.awt.eve nt.ActionEvent evt) (

// TODO add your handling code here:

int $x$;

$x=$ JOptionPane.showConfirmDialog(n ull,"Anda Ingin Yakin Menutup Aplikasi?", "Konfirmasi",JOptionPane. YES_NO_OPTION); if $\left(x==J O p t i o n P a n e . Y E S \_O P T I O N\right)$ 


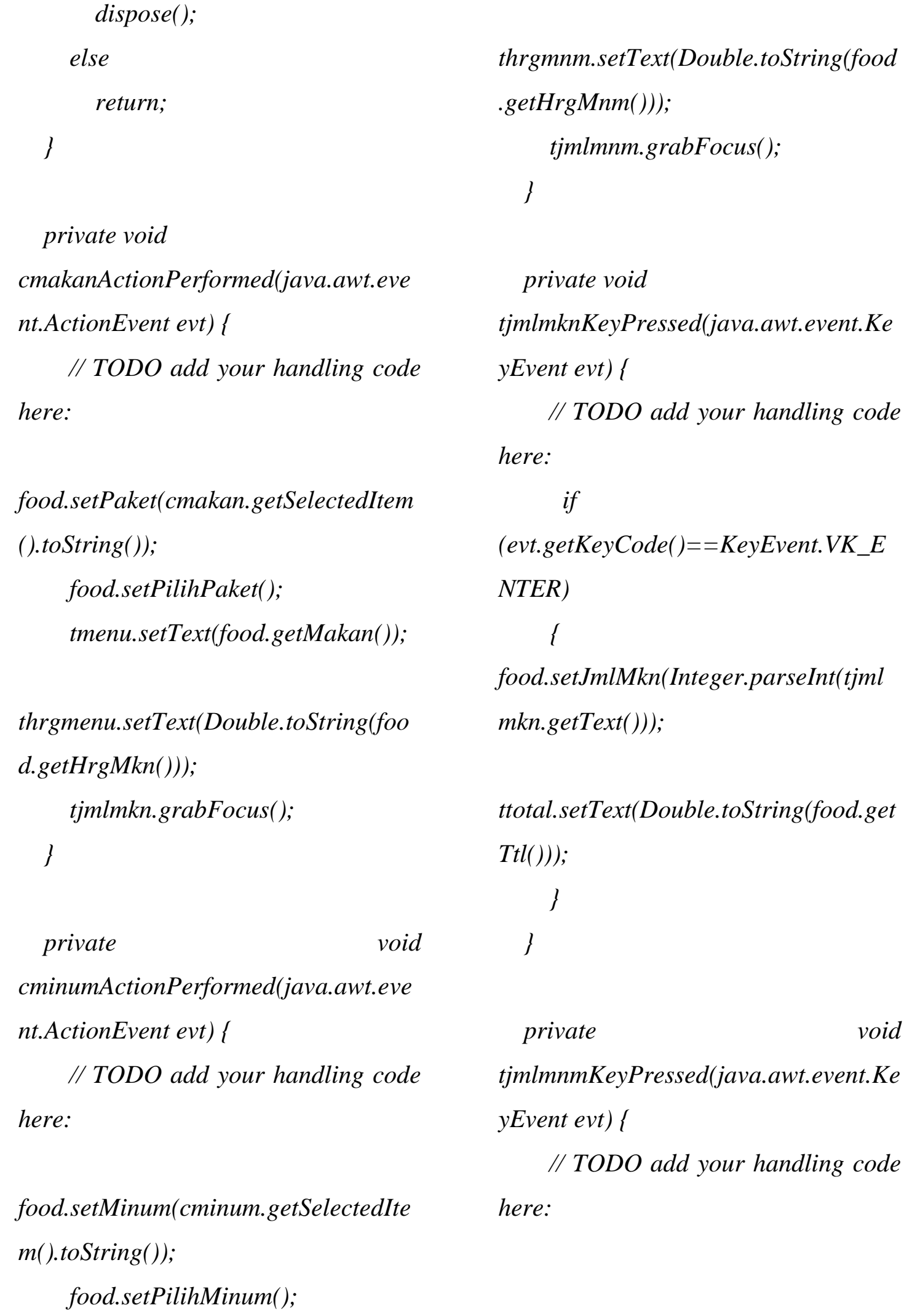

thrgmnm.setText(Double.toString(food .getHrgMnm())); here: 


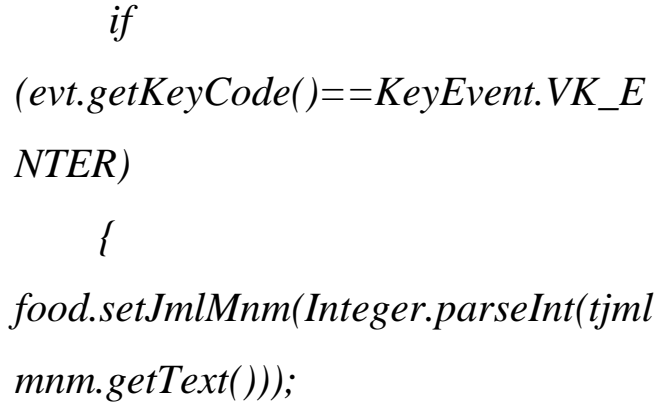

ttotal.setText(Double.toString(food.get Total()));

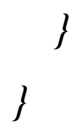
here:
food.setLayan(rbdeliv.getText());

food.setSeleksiLayan();

tdeliv.setText(Double.toString(food.get Biaya()));

ttake.setText("'");

$$
\text { \} }
$$

private

void bhitungActionPerformed(java.awt.eve nt.ActionEvent evt) (

// TODO add your handling code here:

ttotal.setText(Double.toString(food.get Ttl_byr())); tubay.grabFocus();

$$
\text { \} }
$$

$$
\text { private }
$$

void tubayKeyPressed(java.awt.event.KeyE vent evt) \{

$$
\text { // TODO add your handling code }
$$
here:

$$
\text { if }
$$

$\left(\right.$ evt.getKeyCode ()$==K e y E v e n t . V K \_E$

NTER)

$$
\{
$$

food.setUb(Double.parseDouble(tubay $. \operatorname{get} \operatorname{Text}()))$; 


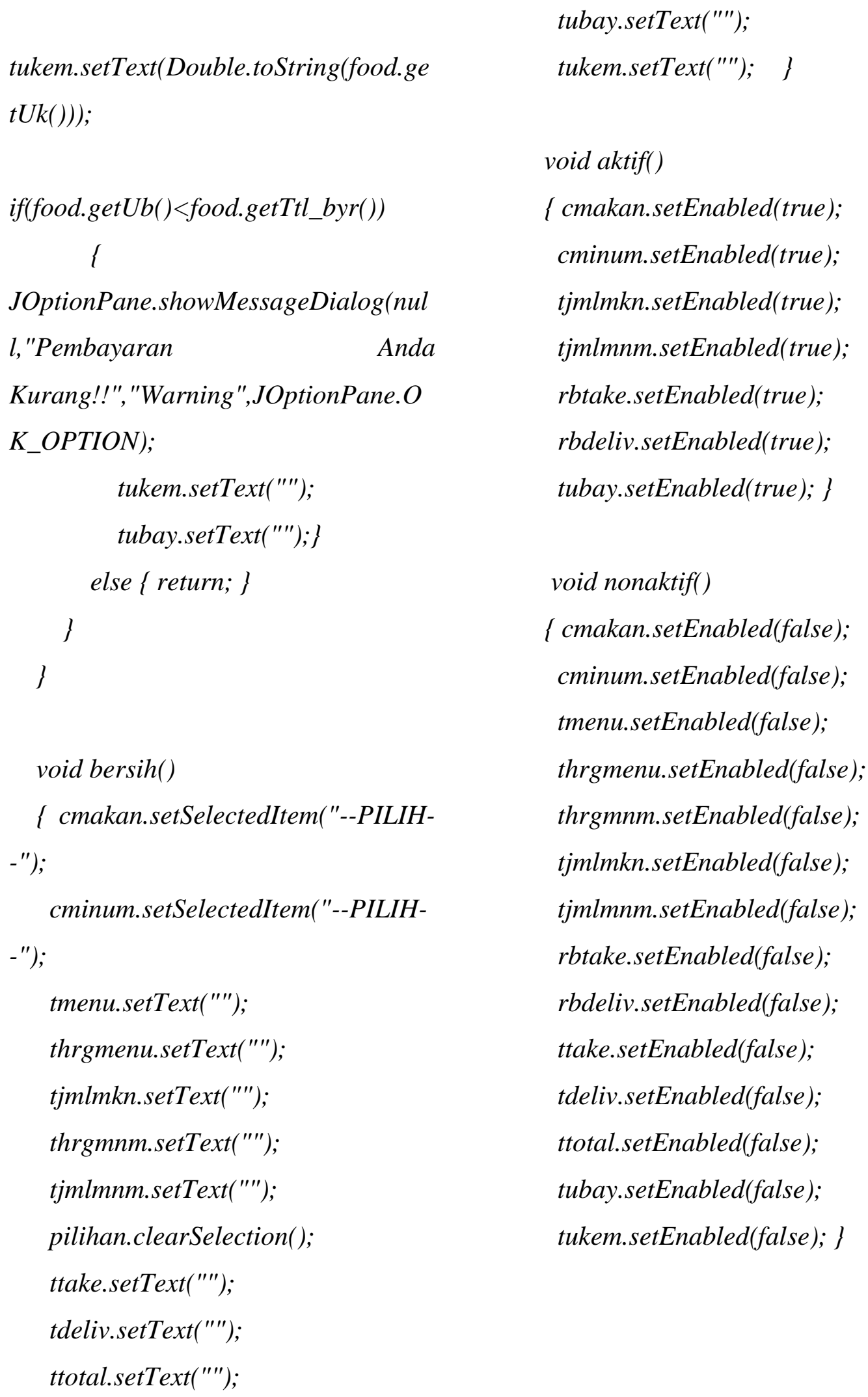




\section{CONCLUSION}

Jadi kesimpulan dari penjelasan di atas ialah bahwa Delphi Merupakan suatu bahasa pemrograman yang memberikan berbagai fasilitas pembuatan aplikasi untuk mengolah teks, grafik, angka, database dan aplikasi web.

Sedangkan OOP/PBO merupakan paradigma pemrograman yang popular saat ini yang telah menggantikan teknik pemrograman berbasis prosedur. Object Oriented Programing yang berarti pula Pemrograman Beorientasi. Pemrograman Berorientasi Objek (Object Oriented Programming/OOP) merupakan pemrograman yang berorientasikan kepada objek, dimana semua data dan fungsi dibungkus dalam class-class atau object-object. Setiap object dapat menerima pesan, memproses data, mengirim, menyimpan dan memanipulasi data.

Pemrograman berorientasi objek berbeda dengan pemrograman prosedural yang hanya menggunakan satu halaman kebawah untuk mengerjakan banyak perintah atau statement. Penggunaan pemrograman berorientasi objek sangat benyak sekali, contoh : java, php, perl, c\#, cobol, dan lainnya.

Dalam konsep Pemrograman Berorientasi Objek dikenal beberapa istilah umum, yaitu:

- Attribute

- Method

- Class

- Object

Konsep-konsep dalam OOP/PBO :

- Abstraction

- Encapsulation

- Inheritance

- Polymorphism

Dan disini juga dijelaskan contoh study kasus Pemrograman Berorientasi Objeck (PBO) dengan menggunakan JAVA . 


\section{DISCUSSION}

Hasil diskusi tersebut ialah Borland Delphi Merupakan suatu bahasa pemrograman yang memberikan berbagai fasilitas pembuatan aplikasi untuk mengolah teks, grafik, angka, database dan aplikasi web. Program ini mempunyai kemampuan luas yang terletak pada produktifitas, kualitas, pengembangan perangkat lunak, kecepatan kompilasi, pola desain yang menarik serta bahasa pemrogramannya terstruktur dan lengkap. Object adalah suatu komponen yang mempunyai bentuk fisik dan biasanya dapat dilihat. Object biasanya dipakai untuk melakukan tugas tertentu dan mempunyai batasanbatasan tertentu. Sedangkan bahasa pemrograman dapat disebut sekumpulan teks yang mempunyai arti tertentu dan disusun dengan aturan tertentu untuk menjalankan tugas tertentu. Gabungan antara object dengan bahasa pemrograman sering disebut bahasa pemrograman berorientasi object.
OOP/PBO merupakan paradigma pemrograman yang popular saat ini yang telah menggantikan teknik pemrograman berbasis prosedur. Object Oriented Programing yang berarti pula Pemrograman Beorientasi Objek sudah ditemukan sekitar tahun 1960 dan dikembangkan pada permulaan tahun 1970 .

Pemrograman Berorientasi Objek (Object Oriented Programming/OOP) merupakan pemrograman yang berorientasikan kepada objek, dimana semua data dan fungsi dibungkus dalam class-class atau object-object. Setiap object dapat menerima pesan, memproses data, mengirim, menyimpan dan memanipulasi data. Beberapa object berinteraksi dengan saling memberikan informasi satu terhadap yang lainnya. Penggunaan pemrograman berorientasi objek sangat benyak sekali, contoh : java, php, perl, c\#, cobol, dan lainnya.

Disini juga menyertakan contoh study kasus menggunakan JAVA Program OOP (Object Oriented Program) dengan Studi Kasus "Food Court

'Oishi

$\mathrm{Ne}^{\prime \prime \prime}$ 
yang disertai dengan proses program dan codingnya .

\section{E. REFERENCE}

[1] O. M. Febriani and A. S. Putra, "Sistem Informasi Monitoring Inventori Barang Pada Balai Riset Standardisasi Industri Bandar Lampung," J. Inform., vol. 13, no. 1, pp. 90-98, 2014.

[2] A. S. Putra, "Paperplain: Execution Fundamental Create Application With Borland Delphi 7.0 University Of Mitra Indonesia," 2018.

[3] A. S. Putra, "2018 Artikel Struktur Data, Audit Dan Jaringan Komputer," 2018.

[4] A. S. Putra, "ALIAS MANAGER USED IN DATABASE DESKTOP STUDI CASE DB DEMOS."

[5] A. S. Putra, "COMPREHENSIVE SET OF PROFESSIONAL FOR DISTRIBUTE COMPUTING."

[6] A. S. Putra, "DATA ORIENTED RECOGNITION IN BORLAND DELPHI 7.0."

[7] A. S. Putra, "EMBARCADERO DELPHI XE 2 IN GPUPOWERED FIREMONKEY APPLICATION."

[8] A. S. Putra, "HAK ATAS KEKAYAAN INTELEKTUAL DALAM DUNIA TEKNOLOGY BERBASIS REVOLUSI INDUSTRI 4.0."

[9] A. S. Putra, "IMPLEMENTASI PERATURAN PERUNDANGAN UU. NO 31 TAHUN 2000 TENTANG
DESAIN INDUSTRI BERBASIS INFORMATION TECHNOLOGY."

[10] A. S. Putra, "IMPLEMENTATION OF PARADOX DBASE."

[11] A. S. Putra, "IMPLEMENTATION OF TRADE SECRET CASE STUDY SAMSUNG MOBILE PHONE."

[12] A. S. Putra, "IMPLEMENTATION

PATENT FOR APPLICATION WEB BASED CASE STUDI WWW. PUBLIKLAMPUNG. COM."

[13] A. S. Putra, "IMPLEMENTATION SYSTEM FIRST TO INVENT IN DIGITALLY INDUSTRY."

[14] A. S. Putra, "MANUAL REPORT \& INTEGRATED DEVELOPMENT

ENVIRONMENT BORLAND DELPHI 7.0."

[15] A. S. Putra, "PATENT AS RELEVAN SUPPORT RESEARCH."

[16] A. S. Putra, "PATENT FOR RESEARCH STUDY CASE OF APPLE. Inc."

[17] A. S. Putra, "PATENT PROTECTION FOR APPLICATION INVENT."

[18] A. S. Putra, "QUICK REPORT IN PROPERTY PROGRAMMING."

[19] A. S. Putra, "REVIEW CIRCUIT LAYOUT COMPONENT

REQUIREMENT ON ASUS NOTEBOOK."

[20] A. S. Putra, "REVIEW TRADEMARK PATENT FOR 
INDUSTRIAL TECHNOLOGY BASED 4.0."

[21] A. S. Putra, "TOOLBAR COMPONENT PALLETTE IN OBJECT ORIENTED PROGRAMMING."

[22] A. S. Putra, "WORKING DIRECTORY SET FOR PARADOX 7."

[23] A. S. Putra, "ZQUERY CONNECTION

IMPLEMENTED

PROGRAMMING

STUDI

CASE PT. BANK BCA Tbk."

[24] A. S. Putra, D. R. Aryanti, and I. Hartati, "Metode SAW (Simple Additive Weighting) sebagai Sistem Pendukung Keputusan Guru Berprestasi (Studi Kasus: SMK Global Surya)," in Prosiding Seminar Nasional Darmajaya, 2018, vol. 1, no. 1, pp. 85-97.

[25] A. S. Putra and O. M. Febriani, "Knowledge Management Online Application in PDAM Lampung Province," in Prosiding International conference on Information Technology and Business (ICITB), 2018, pp. 181-187.

[26] A. S. Putra, O. M. Febriani, and B. Bachry, "Implementasi Genetic Fuzzy System Untuk Mengidentifikasi Hasil Curian Kendaraan Bermotor Di Polda Lampung," SIMADA (Jurnal Sist. Inf. dan Manaj. Basis Data), vol. 1, no. 1, pp. 21-30, 2018.

[27] A. S. Putra, H. Sukri, and K. Zuhri, "Sistem Monitoring Realtime Jaringan Irigasi Desa (JIDES) Dengan Konsep Jaringan Sensor Nirkabel,"
IJEIS (Indonesian J. Electron. Instrum. Syst., vol. 8, no. 2, pp. 221-232.

[28] D. P. Sari, O. M. Febriani, and A. S. Putra, "Perancangan Sistem Informasi SDM Berprestasi pada SD Global Surya," in Prosiding Seminar Nasional Darmajaya, 2018, vol. 1, no. 1, pp. 289-294. 